\title{
Attitudes of some European dental undergraduate students to the placement of direct restorative materials in posterior teeth
}

C. D. LYNCH*, S. E. GUILLEM ${ }^{\dagger}$, B. NAGRANi ${ }^{\dagger}$ A. S. M. GILMOUR ${ }^{\ddagger} \varepsilon$ D. ERIC SON ${ }^{\S} *$ Senior Clinical Lecturer/Honorary Consultant in Restorative Dentistry, Tissue Engineering $\theta$ Reparative Dentistry, School of Dentistry, Cardiff University, Cardiff, ${ }^{\dagger}$ General Dental Practitioner, clo School of Dentistry, Cardiff University, Cardiff, ${ }^{\ddagger}$ Reader/ Honorary Consultant in Restorative Dentistry, Learning o Scholarship, School of Dentistry, Cardiff University, Cardiff, UK and ${ }^{\S}$ Professor in Cariology, Faculty of Odontology, Malmö University, Malmö, Sweden

SUMMARY The aim of this article was to report on the attitudes, opinions and confidences of final year dental students in three European schools towards the restoration of posterior teeth and in particular towards the use of amalgam and resin composite. One hundred and twenty-eight pre-piloted questionnaires were distributed to final year dental students in Cardiff, Dublin and Malmö. The questionnaire sought information relating to various opinions and attitudes towards the use of amalgam and resin composite in posterior teeth. Information was returned anonymously. Ninety-one completed questionnaires were returned (response rate $=71 \%$; Cardiff: $n=40$, Dublin: $n=24$, Malmö: $n=27$ ). Ninety-three per cent of Malmö students $(n=24)$, $67 \%$ of Dublin students $(n=16)$ and $60 \%$ of Cardiff students $(n=24)$ reported that they feel confident when placing posterior resin composites. One hundred per cent of Malmö students $(n=27), 75 \%$ of Cardiff students $(n=30)$ and $33 \%$ of Dublin students $(n=8)$ would prefer to have a resin composite rather than amalgam, placed in one of their own posterior teeth. Eighty-five per cent of Malmö students $(n=23), 30 \%$ of Cardiff students $(n=12)$ and $25 \%$ of Dublin students $(n=6)$ perceive amalgam as being harmful to the environment. For the restoration of a posterior tooth in a pregnant female, $44 \%$ of students $(n=40)$ would place a resin composite restoration, and $7 \%(n=6)$ would place an amalgam restoration, while $32 \%(n=29)$ would place a temporary restoration. Students at Malmö report that they place more posterior resin composites and have greater confidence at placing posterior resin composites than students at Cardiff or Dublin. There was confusion relating to the choice of restorative materials for pregnant females. Large variations in restorative strategies among graduates must be considered as dental professionals can practice in all countries within the European Union.

KEYWORDS: amalgam, dental education, dental student, operative dentistry, posterior composite, resin composite

Accepted for publication 10 May 2010

\section{Introduction}

Changing patterns of dental disease and increases in systemic and oral health, coupled with improved oral hygiene and an awareness of preventive regimes for managing dental caries, have led to increased demands from patients for high quality, aesthetic and minimally invasive restorations for both anterior and posterior teeth (1-3). This is evident in recent primary care-based studies, which have found significant increases in the use of resin composite in posterior teeth (3-5).

Posterior resin composite restorations have been regarded with considerable scepticism, with many authorities until the late 1990s recommending that their use in the load-bearing posterior situations be '... 
limited to the occlusal surfaces of premolars, and preferably those with limited occlusal function...' (6, 7). However, the development of improved resin composite materials and bonding technologies, coupled with an increased understanding of how these materials should be handled has contributed to their increase in clinical use (1-5). This is illustrated by surveys from general dental practice in the early 2000s that indicate that almost one-half of UK dentists routinely placed resin composite in the occlusal surfaces of molar teeth (4). Survival studies, such as a comprehensive review of clinical outcome studies published in the period 19902004 (8), demonstrated that far from being inferior to amalgam, the longevity of direct posterior resin composite restorations is matching, if not exceeding amalgam restorations; this study demonstrating an annual failure rate of $2 \cdot 2 \%$ for posterior direct resin composites, in comparison with $3.0 \%$ for amalgam restorations. This has been confirmed in primary care-based studies that have demonstrated a 10-year survival rate of $82 \cdot 2 \%$ for direct resin composites and $79 \cdot 2 \%$ for amalgam restorations (9).

The demand for posterior resin composite restorations is increasing, requiring competence in this field of restorative dentistry from newly qualified dentists. It is recognised in both the General Dental Council's 'First Five Years' and the Association for Dental Education in Europe guidelines, that on graduation/registration, new dentists are expected to be competent at completing a range of procedures in restorative dentistry, including placement of amalgam and tooth-coloured restorations, and have knowledge of the concepts of minimal intervention (10, 11). Dental graduates of 2009 will be providing dental care for years to come - almost to mid2050s - and their training should be an essential grounding of knowledge and practice to set them in good stead for a professional career in general practice. However, concern has been highlighted regarding the extent and consistency of teaching of posterior resin composites in dental schools in the United Kingdom, Ireland and North America (12-14). The effects of this are also evident in the lack of consistency in the range of clinical techniques used by general dental practitioners when restoring posterior teeth (3).

While many studies have concentrated on the mechanical and physical properties of resin composite $(15,16)$, the content of educational programs on the use of such materials (12-14), or views of general practitioners on their use $(3,5)$, little information exists on the attitudes of final year students to the selection and use of resin composite as a direct restorative material for posterior teeth. Final year dental students are on the verge of independent practice; consequently, their views would be quite revealing as to future use of materials. It has been previously reported that the educational experiences gained at undergraduate dental school shape the skills and techniques utilised in subsequent practice (17). The effect of educational factors must not be underestimated, and in the past has been shown to be more significant than financial factors on the quality of clinical treatments, such as the prescription and fabrication of removable partial dentures (18). Variations in teaching, or lack of clarity, could cause dental graduates some confusion (19). Evidence of variation in teaching between schools is not unique to the teaching of posterior resin composite restorations and has been noted in other areas, such as the teaching of removable partial dentures (20). It is likely that such variations are a reflection of the pressures on contemporary dental education, among others (21).

The aim of this study was to assess the attitudes of final year dental students as to their preference of direct restorative material for use in posterior teeth. The opinions of the students on their teaching, current use, future use and patient and environmental safety of amalgam and posterior resin composite materials were considered in particular. A comparison of the results has been made between students at dental schools in Cardiff, Dublin and Malmö to examine potential differences between these schools. These schools, in particular, were selected as they participate in Erasmus/student exchange programmes, and there are established links between these three schools.

\section{Materials and methods}

A questionnaire was designed with open and closed questions on various issues relating to the restoration of restoring posterior teeth. These included:

1 amount and perceived adequacy of teaching received for restoration of posterior teeth with resin composite;

2 current clinical practices when restoring posterior teeth - including materials preference, and confidence in the use of restorative materials, and influences on materials selection;

3 choice of restorative material for restoration of students posterior teeth;

4 predictions for future use of restorative materials; 
5 attitudes and opinions towards the safety of restorative materials;

6 management of described scenarios (e.g. answering questions to journalists regarding amalgam safety, use of restorative materials in pregnant females).

The questionnaire was pre-piloted on a small group of students and refined. The questionnaire was distributed by hand to all final year dental students in Cardiff, Dublin and Malmö Dental Schools $(n=128)$. All information was collected anonymously, with the exception of knowing which school it came from. The title page informed participants that all replies would be kept anonymous, and the students were asked not to write their names on the questionnaires. Students were informed of their right not to participate in the study.

The data contained in the returned questionnaires were entered into Microsoft Excel. Descriptive statistics are reported.

\section{Results}

A total of 128 questionnaires were distributed (Car$\operatorname{diff}=57$, Dublin $=38$, Malmö $=33$ ). Ninety-one completed questionnaires were returned (response rate $=$ $71 \%)$. Completed responses were received from 40 Cardiff students (response rate $=70 \%, 11$ males, 29 females), 24 Dublin students (response rate $=63 \%, 10$ males, 14 females) and 27 Malmö students (response rate $=82 \%, 15$ males, 12 females).

\section{Amount and perceived adequacy of teaching received for posterior resin composite placement techniques}

Students reported on the amounts of pre-clinical teaching received for both amalgam and resin composite. In Cardiff, students reported that of pre-clinical teaching received for direct posterior restorations, $43 \%$ of this time related to the placement of resin composite, and $57 \%$ related to the placement of amalgam. The corresponding figures for Dublin students were $42 \%$ resin composite and $57 \%$ amalgam, whereas the figures for Malmö were $82 \%$ resin composite and $18 \%$ amalgam.

Malmö students had been taught to place posterior resin composites before receiving instruction in the placement of posterior amalgam restorations, whereas this order was reversed for both the Dublin and Cardiff students.
The teaching of posterior resin composites at the Dublin Dental School was perceived to be adequate by $67 \%$ of students. The students who believed the teaching was inadequate gave reasons such as too little experience, too few teaching sessions and insufficient exposure to a range of materials. The teaching of posterior resin composites in Cardiff Dental School was deemed adequate by $25 \%$ of students. Those students who believed the teaching they received in the placement of posterior resin composites to be inadequate cited reasons such as limited teaching of theory and practice, contradictory information and advice from clinical supervisors, confusion regarding different types of resin composite materials available and moisture control techniques. Ninety-six per cent of Malmö students $(n=26)$ felt the teaching they had received in relation to posterior composites was adequate.

\section{Current clinical practices when restoring posterior teeth}

Ninety-six per cent of the Dublin students $(n=23)$ and $80 \%$ of Cardiff students $(n=32)$ preferred amalgam for use in posterior teeth. In contrast, $100 \%$ of Malmö students $(n=27)$ preferred resin composite for use in posterior teeth.

Ninety-three per cent of students from Malmö $(n=24)$ reported that they feel confident when placing a posterior resin composite restoration. The corresponding figures for Dublin and Cardiff students were 67\% $(n=16)$ and $60 \%(n=24)$, respectively.

Reported influences on choosing amalgam or resin composite for restoration of posterior cavities are summarised in Tables 1 and 2. The most common factors that influenced the decision to place resin composite in a posterior cavity included aesthetic demand $(85 \%$ of Cardiff students, $88 \%$ of Dublin students, $70 \%$ of Malmö students) and moisture control $(98 \%$ of Cardiff students, $79 \%$ of Dublin students, $78 \%$ of Malmö students). Interestingly, while the size of the cavity to be restored had a 'strong influence' on the decision to select composite for $83 \%$ of Dublin students and $58 \%$ of Cardiff students, it was a concern for only $26 \%$ of Malmö students. When considering the placement of amalgam restorations, there was a divergence between the Malmö students and those from Cardiff and Dublin. For example, $92 \%$ of Dublin students and $75 \%$ of Cardiff students considered the size of the cavity to 


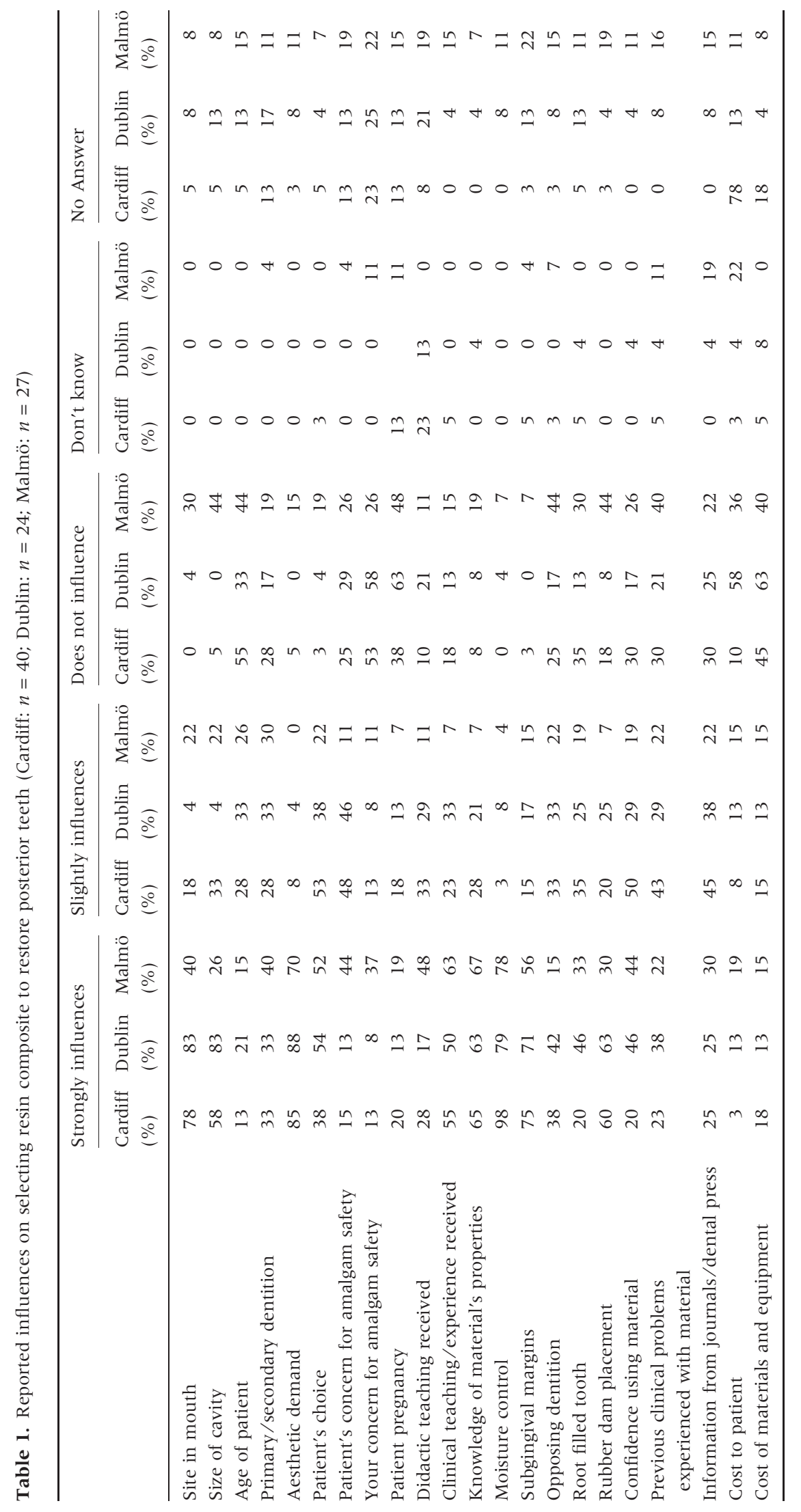




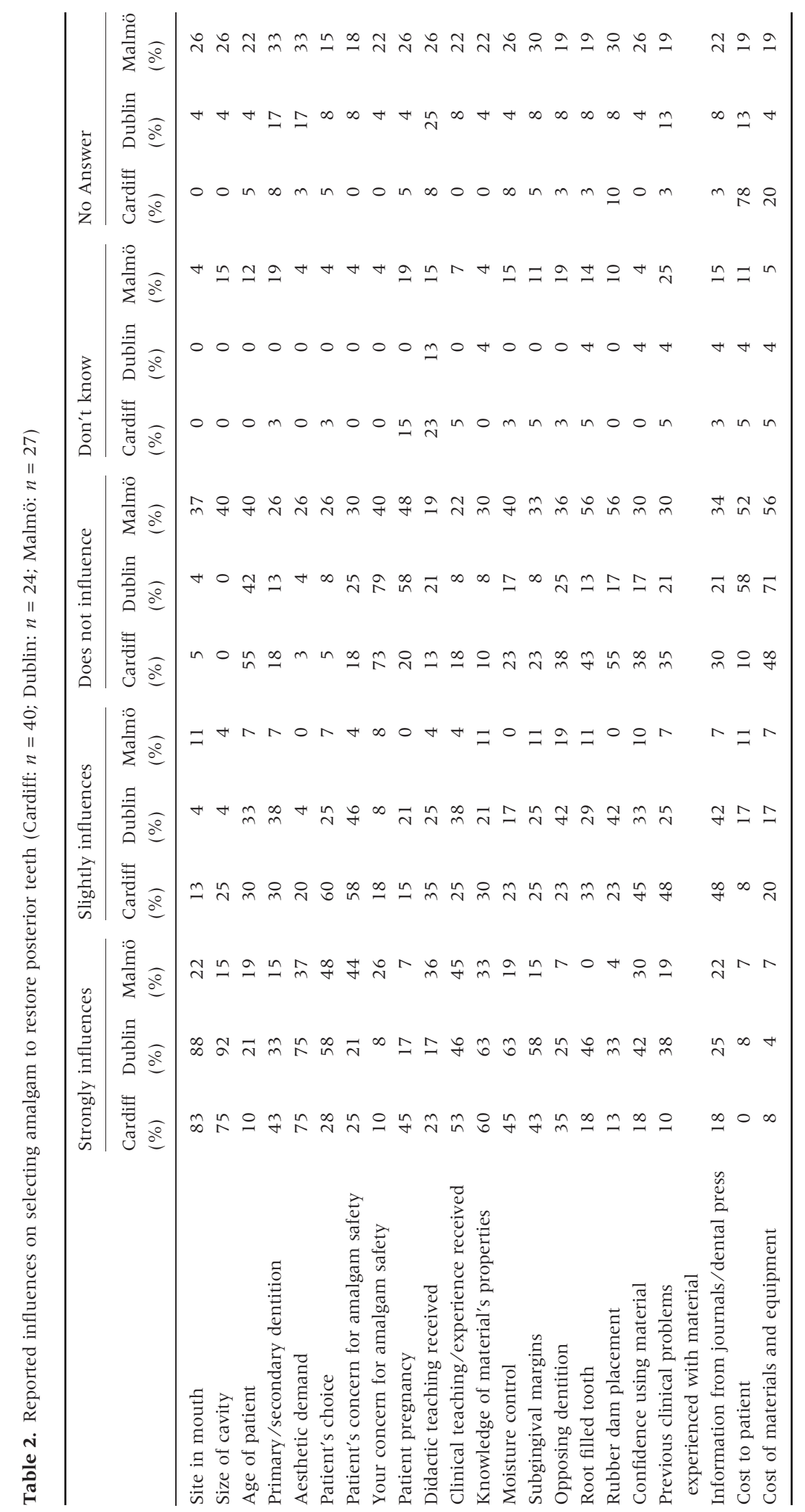


'strongly influence' their selection of amalgam as a restorative material, while only $15 \%$ of Malmö students considered this to be such an important factor. Similarly, $44 \%$ of Malmö students considered the patient's concerns about amalgam safety to influence their decision to place it; this contrasted with a similar view from $25 \%$ of Cardiff students and $21 \%$ of Dublin students.

Choice of restorative material for restoration of students' own posterior teeth

One hundred per cent of the students from Malmö $(n=27)$ preferred to have a resin composite restoration placed in one of their posterior teeth. There were numerous reasons given, the most common being 'aesthetics' ( $n=17)$, followed by 'minimally invasive cavities' $(n=6)$, and that amalgam should be avoided as it is 'bad for environment' $(n=5)$.

Seventy-five per cent of students from Cardiff $(n=30)$ preferred to have a resin composite posterior restoration in one of their own teeth. Twenty-five students out of these 30 students gave 'aesthetics' as a reason. Seventeen per cent $(n=7)$ preferred an amalgam restoration, 5\% $(n=2)$ would prefer a gold inlay and $2 \%(n=1)$ preferred a composite inlay.

Sixty-seven per cent of Dublin students $(n=16)$ preferred amalgam used in their own posterior teeth because of its perceived superior strength, 20\% $(n=5)$ would choose resin composite, because of superior aesthetic qualities. Thirteen per cent $(n=3)$ were undecided, preferring resin composite for aesthetic reasons but amalgam for its physical properties.

\section{Predictions for future use of restorative materials}

In relation to the use of amalgam in general practice:

1 fifty per cent of students from Dublin, 80\% of students from Cardiff and $78 \%$ of students from Malmö believed that the use of amalgam will decrease over the next 5 years;

2 fifty per cent of students from Dublin, 20\% of students from Cardiff and $22 \%$ of students from Malmö believed that the use of amalgam will stay the same over the next 5 years;

3 no students foresaw an increase in the use of amalgam in general practice over the next 5 years.
In relation to the use of resin composite in posterior teeth in general practice:

1 ninety-two per cent of students from Dublin, 87\% of Cardiff students and $67 \%$ of Malmö students believed that the use of resin composite in posterior teeth in general practice will increase over the next 5 years,

2 eight per cent of students from Dublin, 13\% of students from Cardiff and $33 \%$ of students from Malmö believed that the use of resin composite will stay the same over the next 5 years;

3 no students foresaw a reduction in the use of resin composite in general practice over the next 5 years.

Attitudes and opinions towards the safety of restorative materials

Environmental safety In relation to amalgam:

1 eighty-five per cent of Malmö students, 30\% of Cardiff students and $25 \%$ per cent of Dublin students believed amalgam to be harmful to the environment;

2 seventy-five per cent of Dublin students, 70\% of Cardiff students and $15 \%$ of Malmö students did not consider amalgam to be harmful to the environment.

In relation to resin composite:

1 eighty per cent of Dublin and Cardiff students, respectively, and $70 \%$ of Malmö students did not consider resin composite to be harmful to the environment;

2 thirty per cent of Malmö students, and 20\% of Dublin and Cardiff students, respectively, considered resin composite to be harmful to the environment.

Patient safety A Likert scale was used to assess student attitudes to patient safety towards amalgam and composite. This was a discrete number scale from 1 to 10 , with 1 representing 'very safe' and 10 representing 'very harmful'. In relation to amalgam, the majority of Malmö (33\% $n=9)$ and Cardiff students (38\% $n=15$ ) gave a score of ' 3 ', while the majority of Dublin students gave a score of ' 5 '. In relation to resin composite, the majority of students from Cardiff $(45 \%$ $n=18$ ) gave resin composite a patient safety score of ' 1 ', whereas the majority of Malmö students (29\% $n=8$ ) gave a score of ' 2 ', while the majority of Dublin students gave a score of ' 4 '. 


\section{Management of described scenarios}

Students were given two described scenarios and asked to outline how they approach the management of each.

Scenario 1: responding to queries from journalists regarding amalgam safety 'You are a private practitioner; a journalist approaches you and asks your professional views concerning the hazardous nature of dental amalgam with respect to its mercury content. How would you respond?'

A range of responses were given for dealing with this scenario. While many were relatively consistent and focussed on advising the journalist that there was no evidence to demonstrate an association between amalgam restorations and ill-health, there was divergence between the responses from Malmö and those from Cardiff and Dublin. An increased number of students from Malmö highlighted that amalgam restorations, containing mercury, were harmful to the environment.
The responses were grouped and are reported in Table 3.

Scenario 2: use of restorative materials in pregnant females 'You are a private practitioner; a new patient comes to your surgery and in the examination you learn that she is 2 months pregnant and has a few dental amalgam restorations. She presents with a cavity in one of her un-restored posterior teeth. Once you tell her she needs a filling, she informs you that she has researched dental amalgam on the internet and found out that it should not be used as a restorative material in someone who is pregnant. How would you respond to this and what would you restore the cavity with?'

There were again a variety of responses to this scenario: some students felt it best to place a temporary restoration until after birth, some suggested a temporary restoration until after the first trimester. While many felt amalgam was not appropriate in these circumstances, a small number of students were still

Table 3. Responses of students from each school from a journalist who enquires about the safety of dental amalgam (cf. Scenario 1)

\begin{tabular}{|c|c|c|c|c|c|c|c|c|}
\hline \multirow[b]{2}{*}{ Response } & \multicolumn{2}{|c|}{ Cardiff } & \multicolumn{2}{|c|}{ Dublin } & \multicolumn{2}{|c|}{ Malmö } & \multicolumn{2}{|c|}{ Total } \\
\hline & $n$ & $\%$ & $n$ & $\%$ & $n$ & $\%$ & $n$ & $\%$ \\
\hline 'Amalgam is safe' & 11 & 27 & 12 & 32 & - & - & 23 & 25 \\
\hline 'Amalgam is harmful to the environment' & - & - & - & - & 15 & 55 & 15 & 16 \\
\hline 'There is evidence to prove amalgam is safe' & 9 & 22 & 6 & 16 & - & - & 15 & 16 \\
\hline 'There is no evidence to suggest amalgam is harmful' & 6 & 15 & 4 & 11 & - & - & 10 & 11 \\
\hline 'Amalgam has been used safely for a very long time' & 8 & 20 & 1 & 3 & - & - & 9 & 10 \\
\hline 'The mercury content of dental amalgam is very low' & 5 & 12 & - & - & - & - & 5 & 5 \\
\hline 'Members of the dental team are more at risk than the patient' & 4 & 10 & 4 & 11 & 4 & 15 & 4 & 4 \\
\hline 'Amalgam has very good properties' & 3 & 8 & 2 & 5 & 4 & 15 & 3 & 3 \\
\hline 'Explain problems with other materials' & - & - & 1 & 3 & - & - & 1 & 1 \\
\hline 'No comment' & 4 & 10 & - & - & 3 & 11 & 7 & 8 \\
\hline
\end{tabular}

Table 4. Approach by students in each school towards the management of a carious lesion that requires a restoration in a female who is 2 months pregnant (cf. Scenario 2)

\begin{tabular}{|c|c|c|c|c|c|c|c|c|}
\hline \multirow[b]{2}{*}{ Suggested approach } & \multicolumn{2}{|c|}{ Cardiff } & \multicolumn{2}{|c|}{ Dublin } & \multicolumn{2}{|c|}{ Malmö } & \multicolumn{2}{|c|}{ Total } \\
\hline & $n$ & $\%$ & $n$ & $\%$ & $n$ & $\%$ & $n$ & $\%$ \\
\hline Place a resin composite restoration & 13 & 32 & 4 & 17 & 23 & 85 & 40 & 44 \\
\hline Place a temporary restoration until after the pregnancy & 26 & 65 & 3 & 13 & - & - & 29 & 32 \\
\hline Discuss safety issues with the patient & 17 & 42 & 3 & 13 & 8 & 30 & 28 & 31 \\
\hline Use the patients' preference of material & 5 & 12 & 3 & 13 & - & - & 8 & 9 \\
\hline Place an amalgam restoration & 3 & 8 & 3 & 13 & - & - & 6 & 7 \\
\hline Use resin composite if small cavity, amalgam if large cavity & 2 & 5 & 1 & 4 & - & - & 3 & 3 \\
\hline Do further research & - & - & 1 & 4 & - & - & 1 & 1 \\
\hline Explain to the patient that the internet can be an unreliable source & - & - & 1 & 4 & - & - & 1 & 1 \\
\hline Postpone treatment until after the first trimester & - & - & 1 & 4 & - & - & 1 & 1 \\
\hline No response & - & - & - & - & 1 & 4 & 1 & 1 \\
\hline
\end{tabular}


happy to place it. Others felt resin composite was a more appropriate restorative material, while some felt they would be guided by the patient's preferences. The responses were grouped and are reported in Table 4.

\section{Discussion}

This study has surveyed a cohort of final year dental students from three European dental schools in three different countries. These countries have different healthcare systems, different financial remunerative schemes and different regulatory bodies. However, dental graduates can work in either country without further examination or validation, and therefore their education should be of a similar standard and content. The opinions of final year students will have been shaped by their educational experiences, their academic and clinical support and their own research and practice. By surveying these groups of students, it provides a wider perspective of the views of current final year students, and the likely practice of newly qualified dentists over the coming years (17).

A questionnaire is very useful to collect much information in a short space of time and over a broad geographical area, but disadvantages include poor response rates and a self-selection bias. A quite reasonable response rate of $71 \%$ (91 responses out of 128 surveyed) was achieved among students the three dental schools; Cardiff, Dublin and Malmö. This is greater than the suggested acceptable response rate to questionnaires of $64 \%$ (22), and those from other recently published studies on diverse topics such as dental nurse education (53\%) (23), rubber dam usage $(50 \%)(24)$ and local anaesthetic teaching programmes $(18 \%)(25)$. The survey offered students the right to decline to participate; and therefore, it is possible that a form of selection bias may have occurred, in that those students, who are enthusiastic, conscientious and perhaps more knowledgeable about the subject of posterior resin composites, may have been more likely to respond than those who are not so interested in this aspect of clinical dentistry. We also asked respondents to indicate which materials they 'preferred to use', rather than which materials they considered to be in the best interests of their patients. Presumably, dentists more readily place restorations of materials they 'prefer to use', and the data recorded (Cardiff and Dublin: more students prefer to place amalgam rather than resin composite; Malmo: more students prefer to place resin composite than amalgam) give useful information as to the likely habits of this cohort of future dentists when placing restorations in subsequent independent practice.

Differences between the three schools were seen in the amounts of teaching received in the placement of posterior resin composites and the students own perception of the adequacy of teaching. Based on these results, students at Malmö received more teaching in the placement of posterior resin composites, and a greater proportion of Malmö students found this teaching to be adequate than students at Cardiff or Dublin. This is in keeping with previously published information and opinion, which demonstrates that teaching of posterior resin composites in the United Kingdom and Ireland has lagged behind other countries $(12,19,26)$. However, in Scandinavian countries, such as Sweden, there has always been a greater consideration of the environmental hazards of using mercury, including amalgam, which has lead to a greater use of alternative restorative materials, such as composite (27, 28). In fact, recently introduced environmental legislation in Sweden will effectively ban the use of amalgam as a dental restorative material (29). Considering the UK teaching scene, it should also be recognised that the students surveyed (final year class of 07/08) presumably completed their pre-clinical teaching in 2004/2005, which was before the introduction of recommendations from specialist teaching societies, such as the British Association of Teachers of Conservative Dentistry (30) on the teaching of posterior resin composites. These guidelines recommended an increase in the teaching of posterior resin composites and that the initial student experience when restoring posterior teeth should be with resin composite rather than amalgam. At Cardiff, at least, current pre-clinical students are now taught to restore posterior teeth with resin composite before being taught how to do so with amalgam, and the pre-clinical operative dentistry course is mainly focused on the use of resin composite as a posterior restorative material rather than amalgam.

In relation to confidence in clinical procedures, 93\% of students from Malmö $(n=24)$ felt confident in placing a posterior composite restoration; compared to $67 \%$ of students from Dublin $(n=16)$ and $60 \%$ of students from Cardiff $(n=24)$. If newly graduated dentists are not confident in performing procedures using certain materials, it is quite possible that they may steer away from utilising these techniques, and even 
remain incompetent in these specific areas for some time (17). Guidelines from the Association for Dental Education in Europe (11) have stated that the new dentist must be competent to 'restore the tooth to form, function and aesthetics with appropriate materials', while the UK General Dental Council (10) recommend that new graduates are competent 'at completing a range of procedures in restorative dentistry including amalgam and tooth-coloured restorations'. The confidence in placing amalgam restorations was not considered in this questionnaire, and the Malmö students would probably consider themselves unconfident, as the clinical education only occasionally includes placement of amalgam.

Generally, students from all schools do not regard amalgam as being injurious to an individual patient's health. This is in keeping with recent articles that have reported '...there is no important relationship between the number of dental amalgams and body burden of mercury...' and that the '...avoidance of amalgam cannot be justified by the presence of mercury released from dental amalgam...' (31). In relation to potential damage to the environment, there is geographical diversity of opinion, with $85 \%$ of Malmö students, $30 \%$ of Cardiff students and $25 \%$ of Dublin students regarding amalgam as being harmful to the environment. The issue of the environmental safety of amalgam is controversial; studies have demonstrated that the harmful effects of contamination of mercury caused by dental amalgam are insignificant compared to industrial pollution and fossil fuel combustion, with one study demonstrating that the discharge of amalgam from dentistry is supposedly responsible for less than $1 \%$ of the total mercury discharged annually into the environment as a result of human activities $(32,33)$. However, in Sweden, the use of mercury in industrial processing has been reduced considerably, resulting in the increased significance of the mercury waste from dental practices (28) Presumably, this would contribute to a negative perception of dental amalgam in the minds of the general public and within the dental profession.

The dilemma of selecting a suitable posterior restorative material for a pregnant female patient posed difficulty for many of those surveyed. While there is little evidence to suggest what is appropriate in this scenario, advice from the UK Department of Health in the form of a joint statement issued by the Chief Dental Officer and the Deputy Chief Medical Officer is that '...it may be prudent to avoid, where clinically reasonable, the placement or removal of amalgam fillings during pregnancy ...it is not recommended that other permanent, dental filling materials are routinely substituted for amalgam...' (34). While this advice is now more than 10 years old, it does seem to suggest that resin composite restorations are no more suitable than amalgam and that instead temporary restorative materials should be placed in this situation. Although this advice was issued in the United Kingdom, it is still a standard against which clinical practice may be measured. In this study, a small number of students from Cardiff $(n=3)$ and Dublin $(n=3)$ were prepared to place an amalgam restoration in this described scenario - which is a worrying concern. Only $32 \%$ of the overall sample $(n=29)$ reported that they would place a temporary restoration initially and then replace it after the pregnancy was completed.

Completion of dental school education is a major step in the professional development of dental practitioners, which also includes vocational training, continuing professional development, as well as individual experiences in the delivery and implementation of clinical techniques. Implicit within the findings of this study are suggestions that some patients are disadvantaged in not being able to access evidence-based practice in minimally invasive dental treatments. It is recommended that providers of Continuing Professional Development/Continuing Education programmes continue to offer educational opportunities in these areas to improve the quality of treatments available to patients. Let alone this, dental schools should strive towards greater consistency in evidencebased teaching and take notice of educational initiatives, which promote greater harmony in education programmes in this area. An example in the area of posterior resin composites include the already mentioned recommendations from the British Association of Teachers of Conservative Dentistry (30). Further investigations should examine the attitudes and experiences of vocational dental practitioners and young graduates towards posterior composites as they move to independent practice.

\section{Conclusion}

This article has examined and compared the attitudes of 91 final year dental students in three European dental schools. It has found that: 
1 students in Malmö place more posterior resin composites than students at Cardiff or Dublin;

2 students from Cardiff and Dublin were not as confident at placing posterior resin composites as those from Malmö, suggesting that graduating dentists from Cardiff and Dublin may not place as many posterior resin composites as those from Malmö;

3 there was confusion relating to the restoration of posterior teeth in pregnant females.

However, external influences on this teaching, such as environmental legislation in Sweden, should be remembered when considering the results of this study. Further investigation into this area among early career stage practitioners, such as vocational dental trainees and other young graduates, is warranted. Large variations in restorative strategies among graduates must be considered as dental professionals can practice in all countries within the European Union.

\section{Acknowledgments}

We gratefully acknowledge the assistance of all those who took the time to complete our questionnaires.

\section{References}

1. Ritter AV. Posterior composites revisited. J Esthet Restor Dent. 2008;20:57-67.

2. Lynch CD. Successful posterior composites. London: Quintessence Publishing Co., 2008.

3. Gilmour ASM, Latif M, Addy LD, Lynch CD. Placement of posterior composite restorations in United Kingdom dental practices: techniques, problems, and attitudes. Int Dent J. 2009;59:148-154.

4. Burke FJT, McHugh S, Hall AC, Randall RC, Widstrom E, Forss H. Amalgam and composite use in UK general dental practice in 2001. Br Dent J. 2003;194:613-618.

5. Gilmour ASM, Evans P, Addy LD. The use of composite materials in posterior teeth in general dental practice. Br Dent J. 2007;202:E32.

6. Wilson NHF, Dunne SM, Gainsford ID. Current materials and techniques for direct restorations in posterior teeth. Part 2: resin composite systems. Int Dent J. 1997;47:185-193.

7. American Dental Association, Council on Scientific Affairs, Council on Dental Benefit Programs. Statement on posterior resin-based composites. J Am Dent Assoc. 1998;129:1627-1628.

8. Manhart J, Chen H, Hamm G, Hickel R. Review of the clinical survival of direct and indirect restorations in posterior teeth of the permanent dentition. Oper Dent. 2004;29:481-508.

9. Opdam NJ, Bronkhurst EM, Roeters JM, Loomans BA. A retrospective study clinical study on longevity of posterior composite and amalgam restorations. Dent Mats. 2007;23:2-8.
10. General Dental Council. The first five years, 3rd edition (interim). London: GDC, 2008.

11. Plasschaert AJM, Holbrook WP, Delap E, Martinez C, Walmsley AD. Profile and competences for the European Dentist. Eur J Dent Educ. 2005;9:98-107.

12. Lynch CD, McConnell RJ, Wilson NHF. The teaching of posterior composite resin restorations in undergraduate dental schools in Ireland and the United Kingdom. Eur J Dent Educ. 2006; 10:38-43.

13. Lynch CD, McConnell RJ, Wilson NHF. Teaching the placement of posterior resin-based composite restorations in US dental schools. J Am Dent Assoc. 2006;137:619-625.

14. Lynch CD, McConnell RJ, Wilson NHF. Trends in the placement of posterior composites in dental schools. J Dent Educ. 2007;71:430-434.

15. Morin D, deLong R, Douglas WH. Cusp reinforcement by the acid-etch technique. J Dent Res. 1984;63:1075-1078.

16. Watts DC, El Mowafy OM, Grant AA. Fracture resistance of lower molars with class I composite and amalgam restorations. Dent Mats. 1987;3:261-264.

17. Mjör I, Wilson NHF. Teaching of Class I and Class II direct composite resin restorations: results of a survey of dental schools. J Am Dent Assoc. 1998;129:1415-1419.

18. Lynch CD, Allen PF. Why do dentists struggle with removable partial denture design? An investigation of educational and financial issues Br Dent J. 2006;200:277-281.

19. Lynch CD, McConnell RJ, Wilson NHF. Challenges to teaching posterior composite resin restorations in the United Kingdom and Ireland. Br Dent J. 2006;201:747-750.

20. Lynch CD, Allen PF. The teaching of removable partial dentures in Ireland and the UK. $\mathrm{Br}$ Dent J. 2007;203:E17.

21. Kay EJ, O'Brien KD. Academic dentistry- where is everybody? Br Dent J. 2006;200:73-74.

22. Tan RT, Burke FJT. Response rates to questionnaires mailed to dentists. A review of 77 publications. Int Dent J. 1997;47: 349-354.

23. Lynch CD, O’Byrne MT, McConnell RJ, Neville K. Opinions of Irish dental practitioners on dental nurse training. J Irish Dent Assoc. 2003;49:90-94.

24. Lynch CD, McConnell RJ. Attitudes and use of rubber dam by Irish general dental practitioners. Int Endod J. 2007;40: 427-432.

25. Brand HS, Kuin D, Baart JA. A survey of local anaesthesia education in European dental schools. Eur J Dent Educ. 2008;12:85-88.

26. Wilson NHF. Curricular issues changing from amalgam to tooth-coloured materials. J Dent. 2004;32:367-369.

27. Sundberg H, Mejare I, Espelid I, Tveit AB. Swedish dentists' decisions on preparation techniques and restorative materials. Acta Odontologica Scandinavia. 2000;58:135-141.

28. Ylinen K, Loförth G. Nordic dentists' knowledge and attitudes on dental amalgam from health and environmental perspectives. Acta Odontologica Scandinavia. 2002;60: 315-320.

29. Jones DW. Has dental amalgam been torpedoed and sunk? J Dent Res. 2008;87:101-102. 
30. Lynch CD, Shortall AC, Stewardson D, Tomson PL, Burke FJT. Teaching posterior composite resin restorations in the United Kingdom and Ireland: consensus views of teachers. Br Dent J. 2007;203:183-187.

31. Joshi A, Douglass CW, Kim HD, Joshipuri KJ, Park MC, Rimm EB et al. The relationship between amalgam restorations and mercury levels in male dentists and on dental health professionals. J Public Health Dent. 2003;63:52-60.

32. Chin G, Chong J, Kluczewska A, Lau A, Gorjy S, Tennant M. The environmental effects of dental amalgam. Austral Dent J. 2000;45:246-249.
33. Jokstad A, Fan PL. Amalgam waste management. Int Dent J. 2006;56:147-153.

34. Department of Health. Precautionary advice on dental amalgam fillings. (Press release). London: Department of Health, 1998. http://www.dh.gov.uk/en/Publicationsand statistics/Pressreleases/DH_4024646. Accessed on June 6th 2009.

Correspondence: Dr Christopher D. Lynch, School of Dentistry, Cardiff University, Heath Park, Cardiff, CF14 4XY, UK.

E-mail: lynchcd@cardiff.ac.uk 